\title{
Impact Strength Analysis of Plate Panels with Welding-Induced Residual Stress and Deformation
}

\author{
Yehia Abdel-Nasser'1, Ninshu Ma², Sherif Rashed', Hidekazu Murakawa² \\ ${ }^{1}$ Naval Architecture and Marine Engineering, Faculty of Engineering, Alexandria University, Alexandria, Egypt \\ 2Joining and Welding Research Institute, Osaka University, Osaka, Japan \\ Email: yehia-nasser@hotmail.com,ma3liang@yahoo.co.jp
}

Received 19 October 2015; accepted 11 January 2016; published 14 January 2016

Copyright (C) 2016 by authors and Scientific Research Publishing Inc.

This work is licensed under the Creative Commons Attribution International License (CC BY). http://creativecommons.org/licenses/by/4.0/

c) (i) Open Access

\section{Abstract}

The paper describes the simulation of impact loads applied on plate panels with welding-induced residual stresses and deformation (WSD). Numerical simulations using FEM are carried out to study the influence of welding-induced residual stresses and deformation on the impact strength of plate panels. Welding is simulated using a three dimensional thermal mechanical coupled finite element method. The welding stress and deformation are taken as the initial imperfections in the impact strength analysis and their influence on the behavior of plate panels subjected to impact loadings. The impact loadings from the three directions, the lateral direction and two in-plane directions of the plate panels are studied. Results show a certain reduction in the impact strength due to the existence of welding stress and deformation in the plate panels. It is found that the reduction of impact force is strongly influenced by the welding deformation and the impact directions in the plate panels. This reduction is more significant when the impact force is in the lateral direction.

\section{Keywords}

Lateral Impact, In-Plane Impact, Welding Deformation, Plate Panels, Impact Force, FEM

\section{Introduction}

The structural design of ships concerning grounding and collision requires an accurate prediction of the damage of plate panels under impact loading. Several experimental works on laterally loaded panels have been conducted in order to derive analytical expressions [1]. Collision is considered as a time-depended nonlinear dy-

How to cite this paper: Abdel-Nasser, Y., Ma, N., Rashed, S. and Murakawa, H. (2016) Impact Strength Analysis of Plate Panels with Welding-Induced Residual Stress and Deformation. World Journal of Mechanics, 6, 8-17. 
namic phenomenon. The majority of researchers have focused on deriving the resultant damage of the ship collisions via analytical, experimental, and finite element methods. Hagiwara et al. [2] proposed a method for predicting low-energy ship collision damage based on experiments and determined the initiation of plate fracture. Cho and Lee [3] developed a simplified method for the prediction of the extent of damage of stiffened plates due to lateral collisions. Ehlers et al. [4] performed numerical simulations of the collision response of ship side structures and investigated sensitivity of the various failure criteria. Villavicencio and Soares [5] studied numerically the deflection and failure of small panels subjected to lateral impact using different stiffening systems and impact locations. However, literatures on the investigation of the effect of welding induced initial welding stresses and deformation (WSD) on the impact strength of plate panels are limited. Generally, the evaluation of impact strength of plate panels is based on the shape of initial welding imperfections and material properties with the consideration of the plastic strain. Ma, et al. [6] and Takada et al. [7] proved that the material failure must be considered in the impact simulation in order to accurately evaluate the impact strength. Also, the effects of dimension error, plastic strain and residual stresses due to welding have to be studied. In this paper, the influence of welding induced residual stresses and deflections is taken into considerations for plate panels subjected to impact loadings. Two different directions of impacts such as lateral impact and in-plane impact are modeled to investigate the behavior of plate panels. Finite element analysis is a useful tool to predict the impact strength of plate panels. The paper summarizes the results from numerical simulations of plate panels subjected to in-plane and lateral impact loadings. The influence of the initial welding imperfection on the force-displacement response is reviewed. Results show a reduction in the impact strength due to the occurrence of initial welding imperfections in the plate panels. The reduction of impact force is found to be dependent on the mode of initial deflection and direction of loading in the plate panels. However, the nonlinear dynamic analysis should be compared with experimental scaled tests to verify the results.

\section{Computation Methods and Procedures}

This research work is aimed to investigate the influence of welding-induced residual stresses and deformation (WSD) on the impact strength of plate panels. Since experimental investigations on partial and/or full scale welded plate panels are difficult, FEM is often used to simulate the impact behaviors of plate panels subjected to a striking object such as a ball or a rigid frame. The previous study [8] showed that simulation results on the deformation and impact forces of hybrid plate panels agreed very well with experimental ones. Therefore, in this study, the simulation methods, simulation models and their results are focused.

The computation methods and procedures used in analyzing impact strength of plate panels with welding-induced residual stresses and deformation are summarized in Figure 1 as follows:

- Three dimensional welding heat conduction analysis on a butt welded plate panel is carried out using a research version of the in-house FEM solver JWRIAN developed by authors [9].

- A coupled thermal-elastic plastic analysis is performed to estimate the welding residual stresses and deformation using the in-house software JWRIAN.

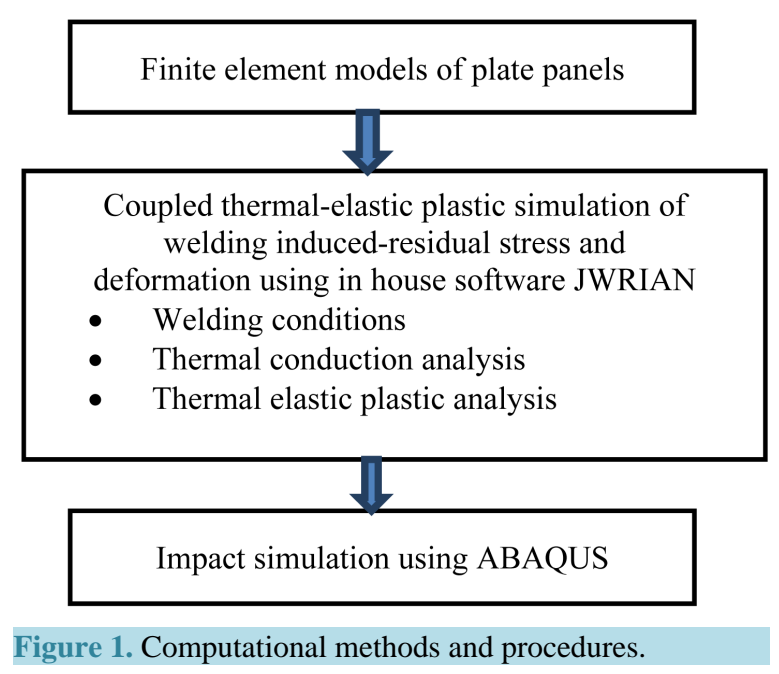


- Implicit dynamic analyses using ABAQUS Ver. 6-13 [10] are carried out to simulate the deformation behaviors of the plate panel under impact loadings in different directions.

- Material properties of plate panels and its characteristics are as shown in Table 1 [11]. Strain rate effect was not considered in this analysis.

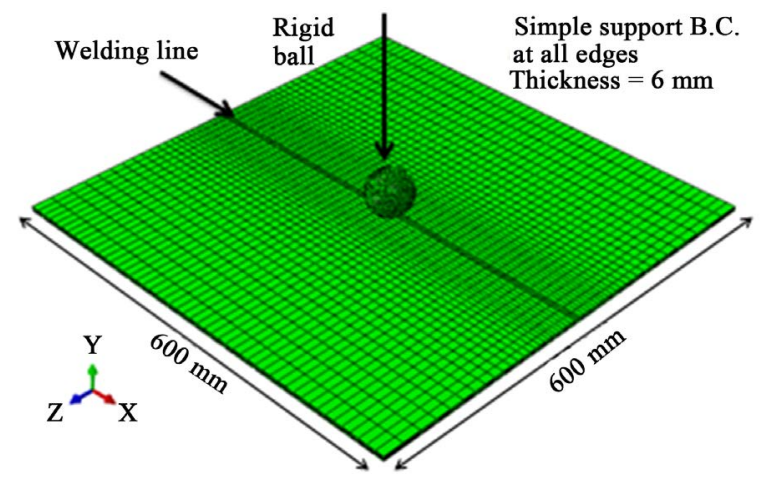

(a)

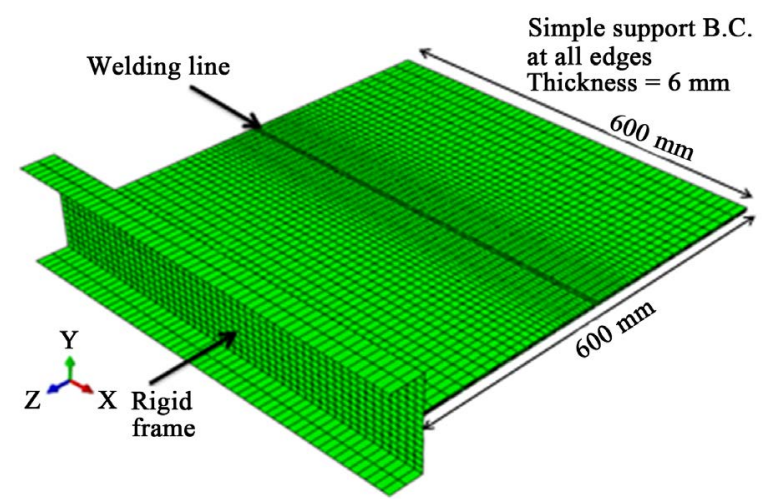

(b)

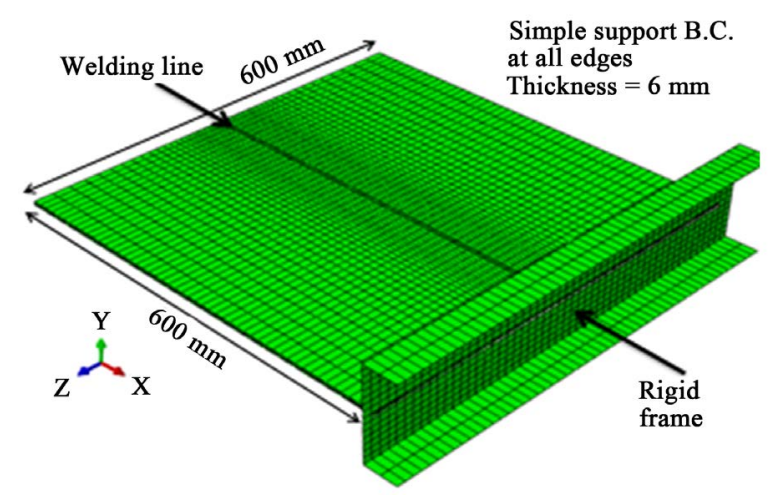

(c)

Figure 2. (a) Plate panel impacted by a rigid ball in direction Y; (b) Plate panel impacted by a rigid frame in-plan direction-Z; (c) Plate panel impacted by a rigid frame in-plan direction-X.

Table 1. Mechanical properties of the material.

\begin{tabular}{|c|c|c|c|c|}
\hline \multicolumn{5}{|c|}{ Mechanical properties of the material } \\
\hline Young's & Poisson & Yield & Tensile & Failure \\
\hline Modulus & Ratio & Stress & Stress & Strain \\
\hline 210 Gpa & 0.3 & 320 Мра & 480 Мра & $35 \%$ \\
\hline
\end{tabular}




\section{Plate Panel and FEM Models}

A square plate panel $600 \times 600 \times 6 \mathrm{~mm}$ is modeled using eight node hexa elements as shown in Figure 2(a). A fine mesh of size $2 \times 2 \mathrm{~mm}$ is adopted at the welding line with four elements through the plate thickness. A gradually coarsened mesh towards the plate edges is adopted to save computational time. The plate panel is assumed simply supported at all edges. The impactor (ball or frame) is modeled as a rigid body. An artificial mass is concentrated at the center of the impactor. An initial impact velocity was assigned to the impactor in the motion direction and other degrees of freedom were constrained. Different directions of impact loadings are investigated, namely lateral and in-plane loadings as shown in Figures 2(a)-(c), respectively.

\section{Welding Residual Stresses and Deformation}

The effect of initial imperfections, welding residual stresses and deformation (WSD), are taken into account in the plate panel when subjected to impact loadings. A volumetric heat source is applied through the welding line. The problem is treated as a de-coupled thermal-mechanical analysis. However, temperature dependent mechanical properties are used. First, a thermal analysis was performed to predict the temperature history of the plate panel. Subsequently, thermal loads induced by transient welding temperature fields were applied to the plate panel and residual stresses were predicted using a nonlinear thermal elastic plastic FEM [12]. Results of analyses such as temperature, welding residual stresses and deformation are shown in Figure 3.

\section{Impact Analyses}

\subsection{Lateral Impact in Y-Direction}

By considering the welding residual stresses and deformation (WSD) shown in Figure 3 as initial welding im-

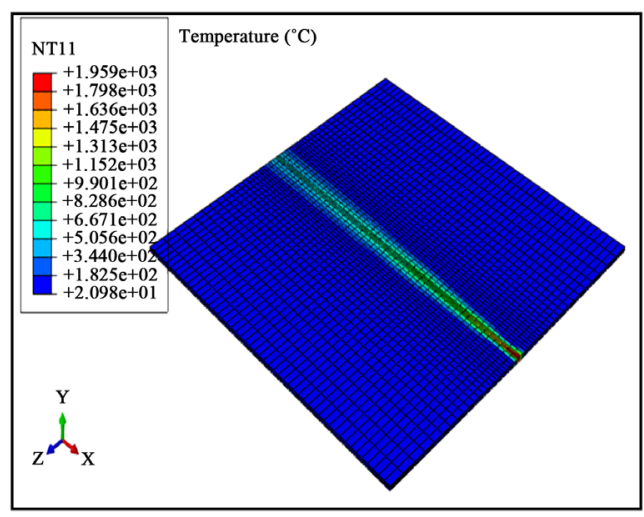

(a)

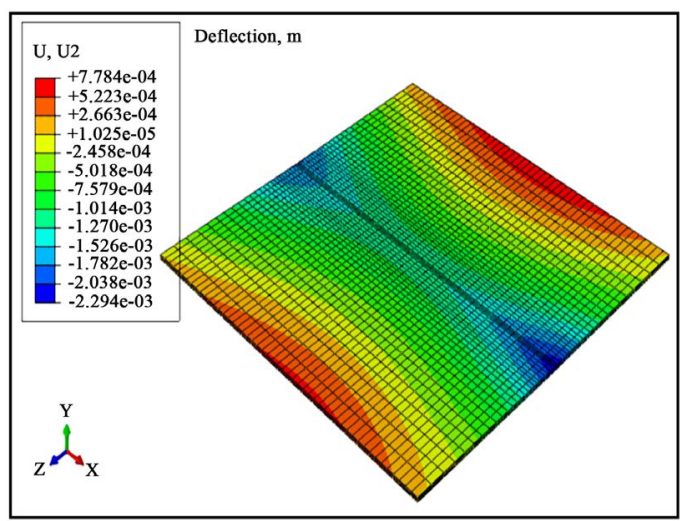

(c)

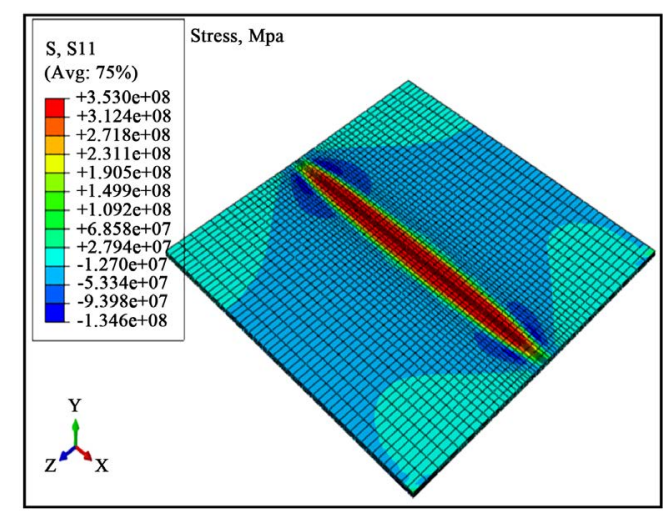

(b)

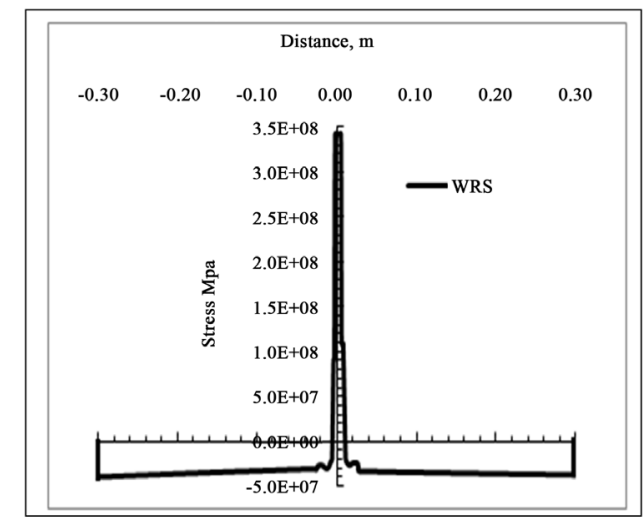

(d)

Figure 3. Welding residual stresses and deformation computed by thermal elastic plastic FEM. (a) Temperature distribution; (b) Distribution of residual stress-X; (c) Deflection mode; (d) Residual stress-X distribution in Z-direction. 
perfections, a lateral impact loading in Y-direction is applied as shown in Figure 2(a). A virtual mass of $200 \mathrm{~kg}$ and an initial velocity of $6 \mathrm{~m} / \mathrm{sec}$ are concentrated at the center of the impactor (rigid ball). Here, a plate panel without WSD is referred to as "flat plate" while the plate panel with the considered initial imperfections is referred to as "plate with WSD". Figure 4 and Figure 5 show the deformation due to impact loading of the flat plate and the plate with WSD, respectively. It is observed that the two plates have the same deflection mode. However, the maximum deflection at the center of the plate with WSD reached $57 \mathrm{~mm}$ which is larger than the maximum deflection of $49 \mathrm{~mm}$ in the case of the flat plate. After the velocity of the impact ball becomes equal to zero, the ball rebounds and the deflection of the plate panel decrease. Figure 6 shows the stress distribution during the impact loading. Figure 7 shows relationships between impact force and displacement of the ball. The plate with WSD attained lower impact force than that of the flat plate. This is because that the stiffness of the plate panel with WSD is reduced by initial welding imperfections from the beginning of loading. In this type of impact, the initial welding imperfections reduced the impact strength of the plate panels significantly. After yielding, plasticity spreads in the central part of the plate panels which increases the reduction of the impact force for the both plates.

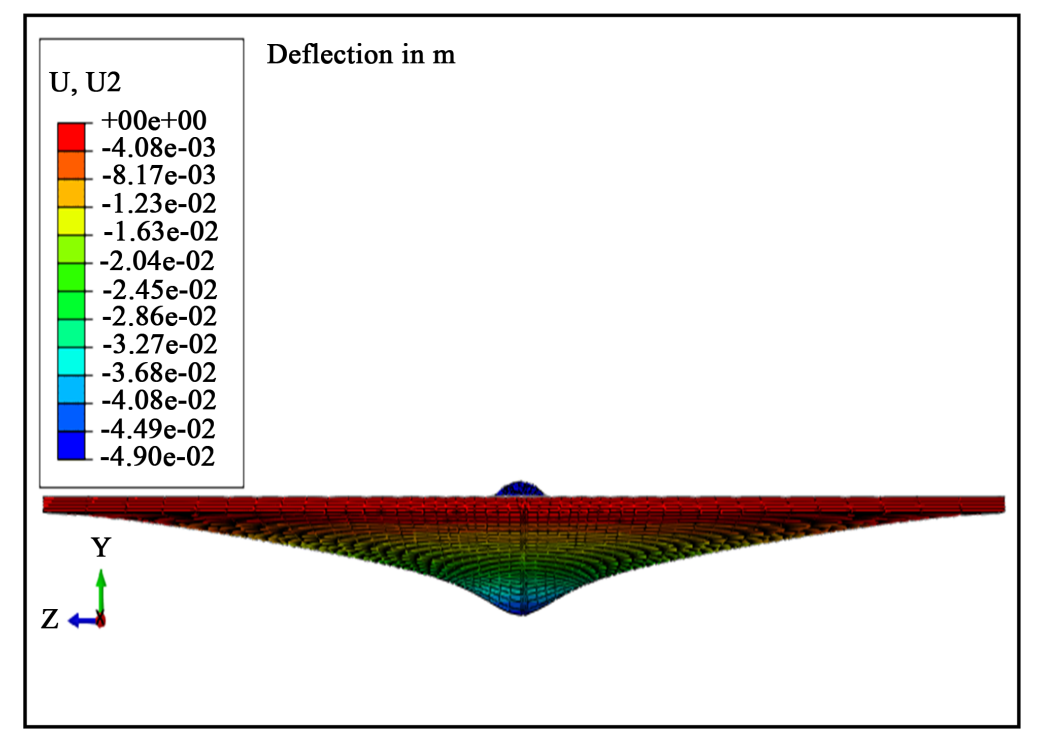

Figure 4. Deflection mode for flat plate.

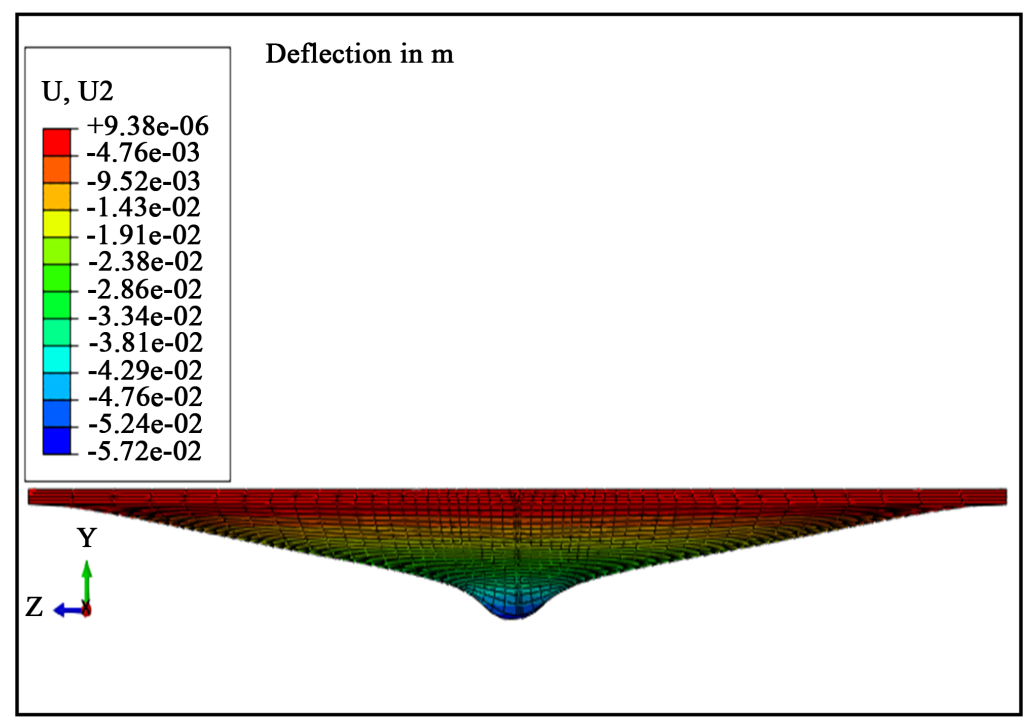

Figure 5. Deflection mode for plate with WSD. 


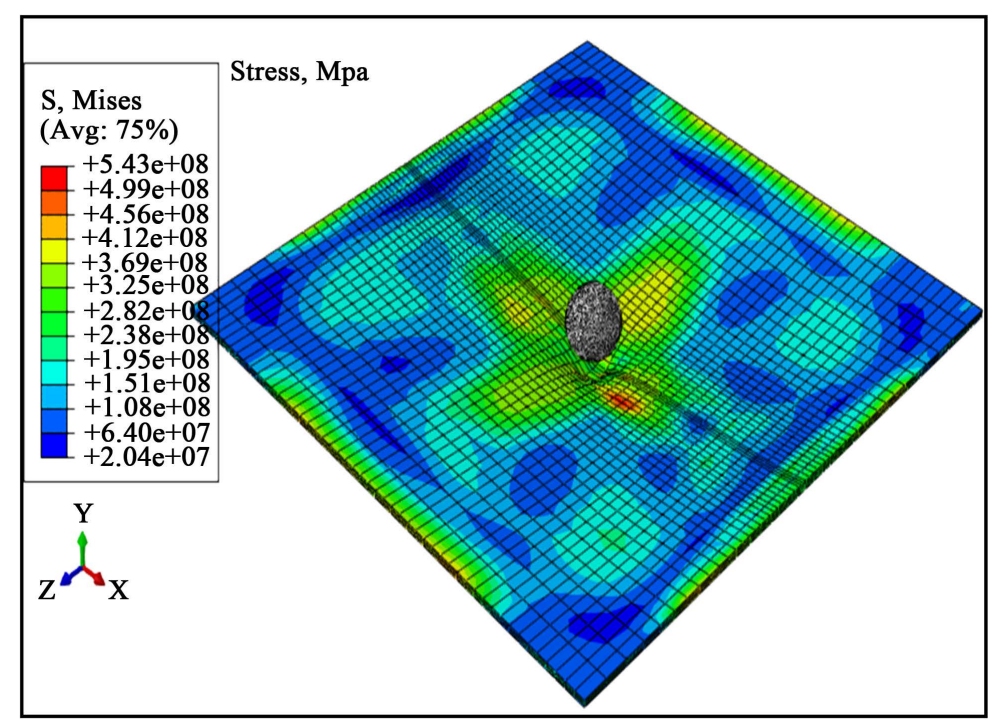

Figure 6. Stress and deformation of plate with WSD.

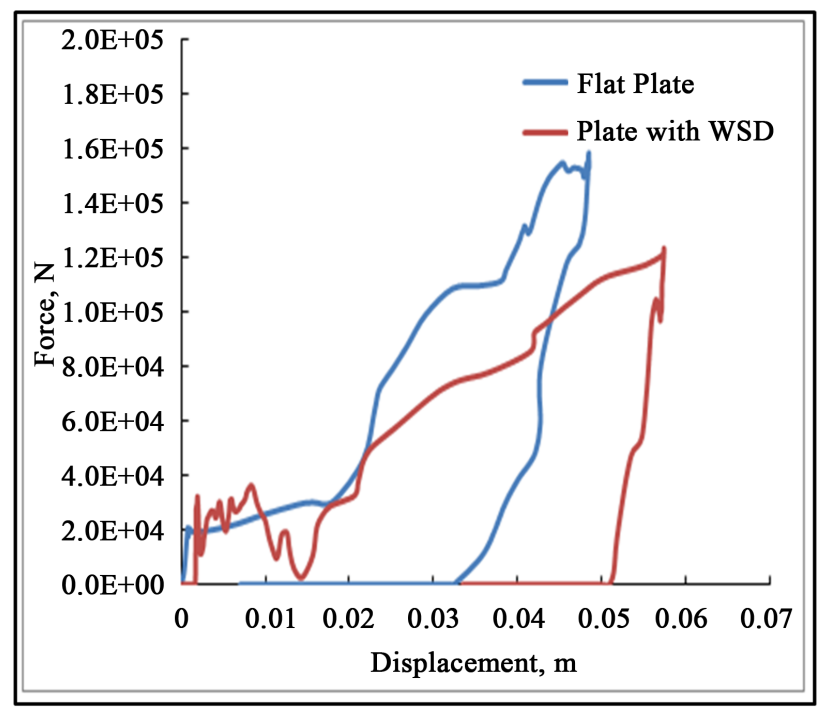

Figure 7. Force-displacement relationships.

\subsection{In-Plane Impact in Z-Direction}

In this section, in-plane impact loading in Z-direction as shown in Figure 2(b) is investigated. This case is typically similar to the case of the plate of web frame and subjected from outside to impact loading. A virtual mass of 10,000 $\mathrm{kg}$ and an initial velocity of $6 \mathrm{~m} / \mathrm{sec}$ are concentrated at the reference point of the impactor (Rigid frame). For plate panels with WSD, the maximum deformation as shown in Figure 8 is observed at the center of the plate panel (at the weld line) with a value equal to $50 \mathrm{~mm}$. While the maximum deflection of the flat plate as reached about $35 \mathrm{~mm}$ and it is far from the center of the plate as shown in Figure 9. Here, the deflection mode of the flat plate is somewhat different from that of the plate with WSD. The deflection mode of the flat plate looks like a buckling mode. Mises stress and deformation of the plate with WSD produced by impact loading are shown in Figure 10. Figure 11 shows relationships between the impact force and displacement of the rigid frame. During the elastic state, force and displacement relationships are similar. Deviations are observed after the spread of plasticity. The two plates have almost the same maximum impact force. However, the plate with WSD showed fast decrease of the impact force after the spreads of plasticity. On the other hand, the flat plate has sustained additional load after yielding and then the impact force decreased. It can be understood that the 


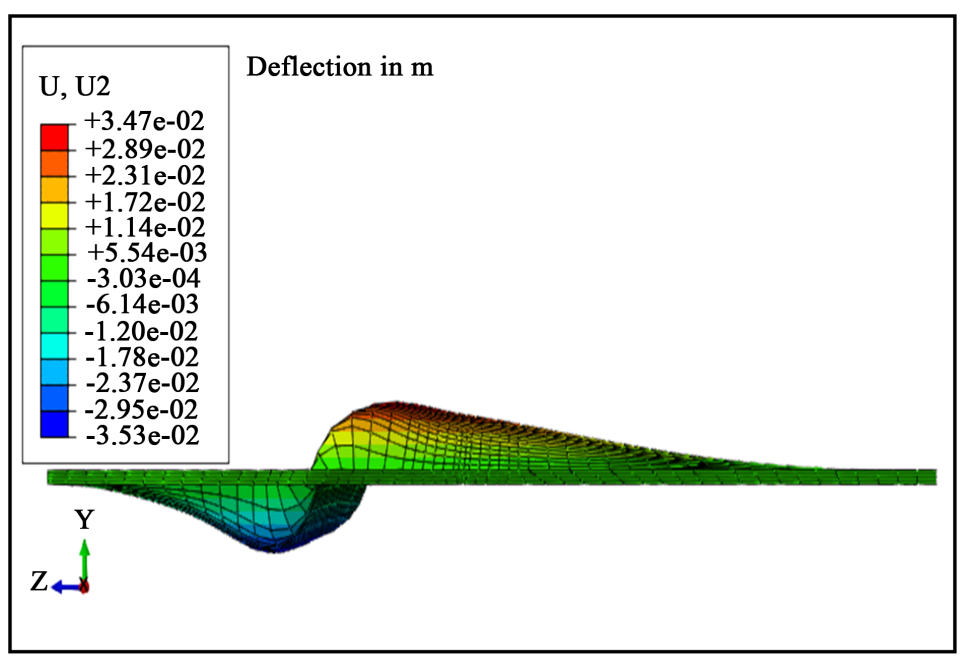

Figure 8. Deflection mode for flat plate.

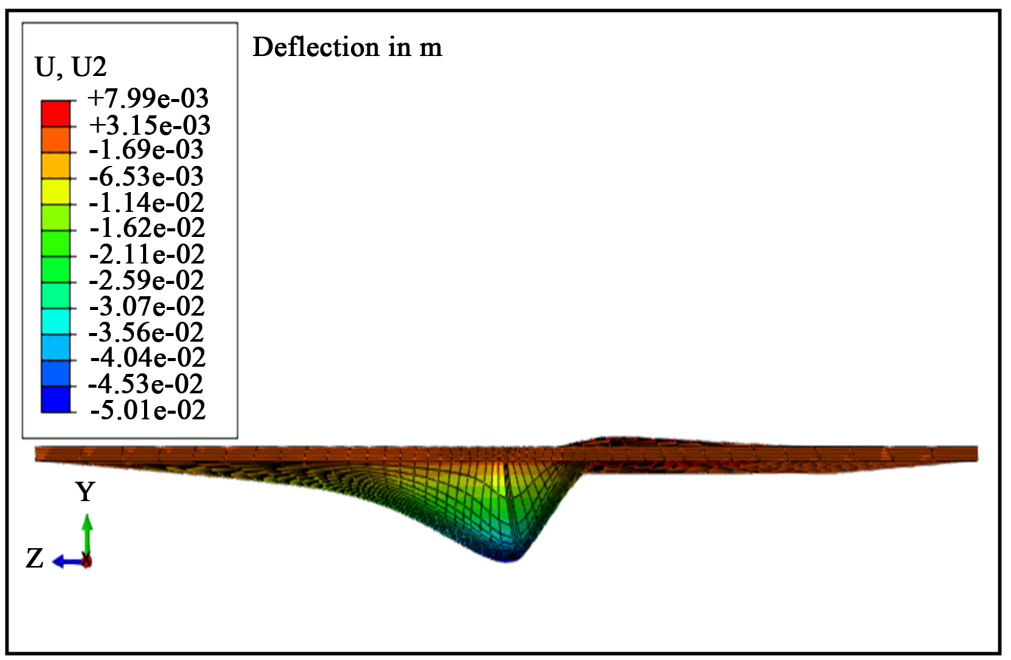

Figure 9. Deflection mode for plate with WSD.

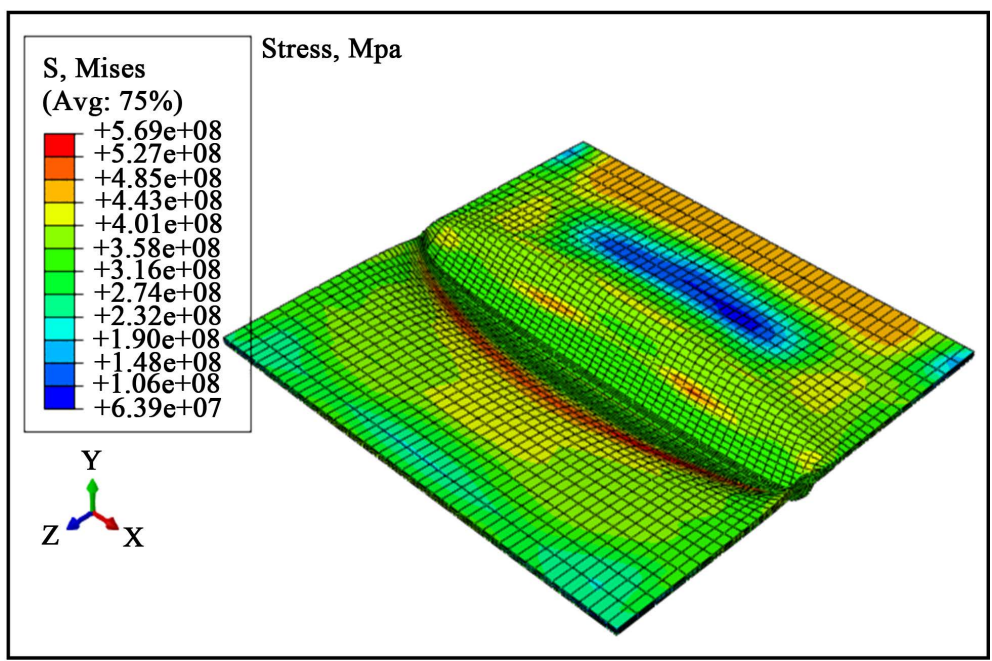

Figure 10. Stress and deformation of plate with WSD. 


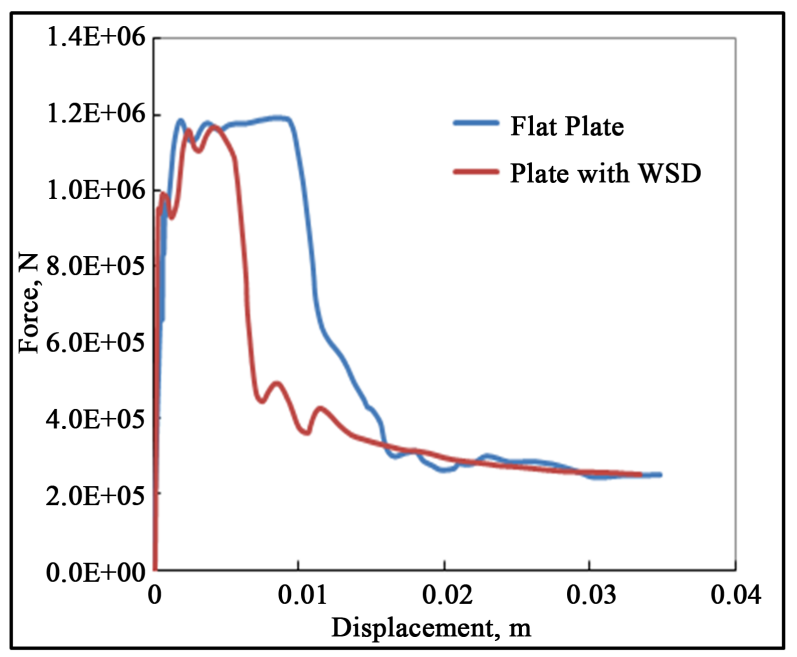

Figure 11. Force-displacement relationships.

two plates have almost the same initial stiffness. The influence of the initial welding imperfections on impact deformation near the center of the plate can be clearly observed. The deflection mode of the plate with WSD follows the mode of initial deflection, while the flat plate has a strong effect on a post buckling mode.

\subsection{In-Plane Impact in X-Direction}

In this section, in-plane impact loading in X-direction as shown in Figure 2(c) is investigated. Previous initial conditions due to welding of the plate panel are applied. Also, the same values of virtual weight and initial velocity are concentrated at the center of the rigid frame. For both the plate panel with WSD and the flat plate, the maximum deflections are observed far from the center of the plate panel. Although the plate panel has same initial conditions and same acting impact load, values of the maximum deflections in this case of impact are less than those in the case of impact in Z-direction. Also, the deformation modes of the plate WSD and the flat plate are similar as shown in Figure 12 and Figure 13. Both plates deflect in the post buckling mode. Figure 14 shows the stress and deformation of plate panel with WSD during impact loading. Figure 15 shows relationships between impact force and displacement. Initially, the two plates have almost the same stiffness. Also, the two plates have almost the same maximum impact force. When plastic deformation has occurred, the load carrying capacity of the plate with WSD starts to decrease causing the impact force to rapidly decrease. However, the flat plate sustains a little more load after yielding. In this type of impact loading, the influence of the initial welding imperfections is less significant on the behavior of the plate panels than in the case of impact in Z-direction.

\section{Conclusions}

The paper refers to the simulation impact of plate panels with welding stress and deformation (WSD). Two different directions of impact loadings on plate panels such as lateral impact and in-plane impacts are investigated. The following related aspects are considered to be essential for such a research work:

- Whatever the direction of impact loading, the occurrence of welding stress and deformation has a significant role in the reduction of the impact strength of the plate panels. The reduction of impact force is found to be dependent on the mode of initial deflection and direction of impact loading in the plate panels. The reduction is more significant when the impact force is in the lateral direction.

- Regarding to lateral impact, the stiffness of the plate panel with WSD is reduced from the beginning of impact loading. After yielding of the plate panel, the impact force is drastically decreased and its value reaches to zero force.

- Regarding to in-plane impact in Z-direction, the deflection mode for the plate panel with WSD follows the mode of initial deflection, while the flat plate behaves post buckling mode. For in-plane impact in X-direction, the influence of the initial welding imperfections is less significant on the impact strength and behavior of the plate panels. 


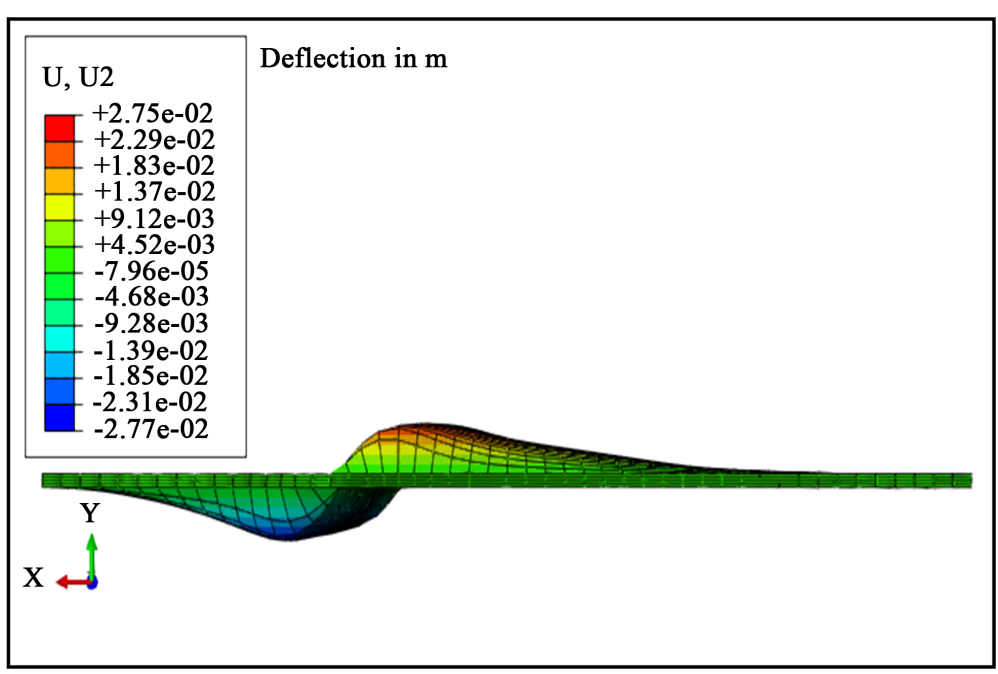

Figure 12. Deflection mode for flat plate.

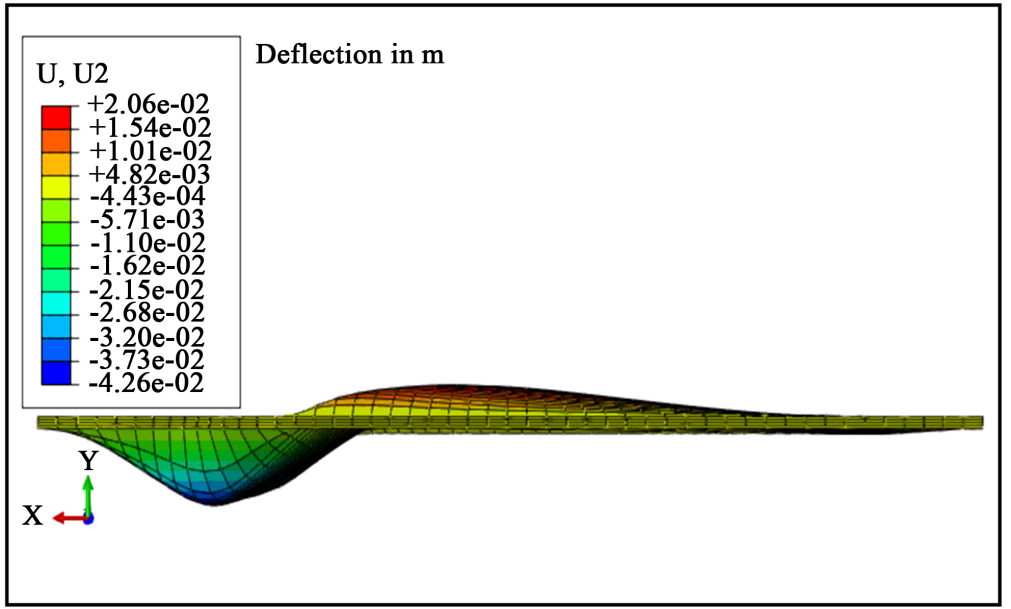

Figure 13. Deflection mode for plate with WSD.

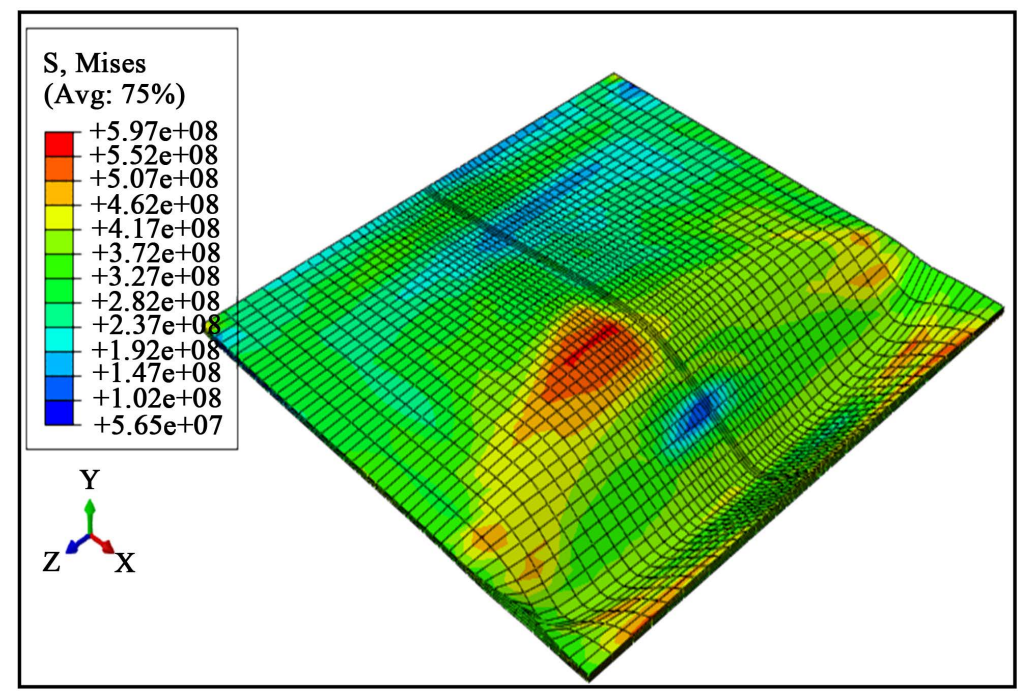

Figure 14. Stress and deformation of plate with WSD. 


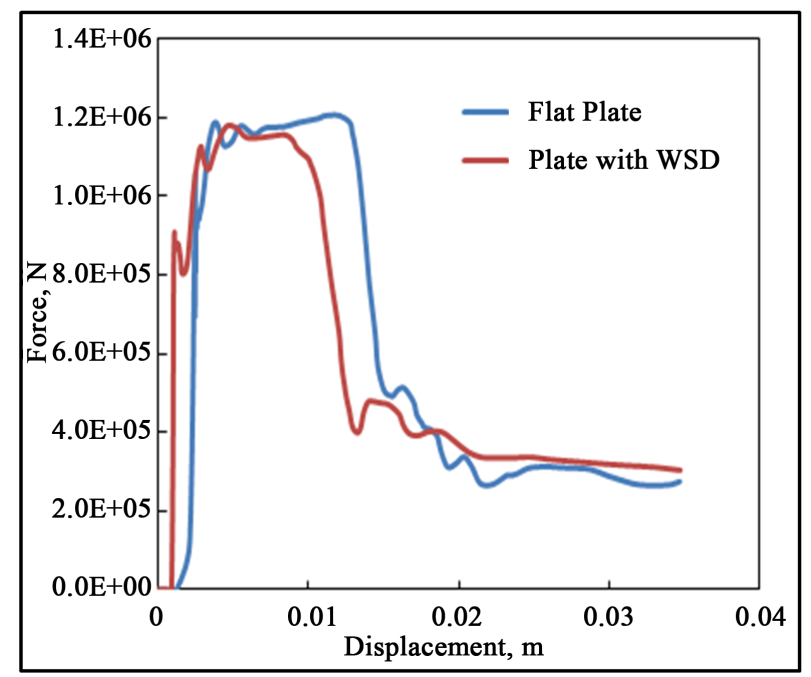

Figure 15. Force-displacement relationships.

- As the value of initial deflection is increased in the plate panels, as the reduction in the impact force is increased.

\section{Acknowledgements}

Authors would like to express their acknowledgments to Mr. Hui Huang, JWRI, Osaka University for his support in simulation works.

\section{References}

[1] Brown, A.J. (2002) Modeling Structural Damage in Ship Collisions. SSC -1400 Report.

[2] Hagiwara, K., Takanabe, H. and Kawano, H. (1983) A Proposed Method of Predicting Ship Collision Damage. International Journal of Impact Engineering, 1, 257-279. http://dx.doi.org/10.1016/0734-743X(83)90022-2

[3] Cho, S.R. and Lee, H.S. (2009) Experimental and Analytical Investigations on the Response of Stiffened Plates Subjected lo Lateral Collisions. Marine Structures, 22, 84-95. http://dx.doi.org/10.1016/j.marstruc.2008.06.003

[4] Ehlers, S., Broekhuijsen, J., Alsos, H.S., Biehl, F. and Tabri, K. (2008) Simulating the Collision Response of Ship Side Structures: A Failure Criteria Benchmark Study. International Shipbuilding Progress, 55, 127-144.

[5] Villavicencio, R., Liu, B. and Guedes Soares, C. (2012) Response of Stiffeners with Attached Plate Subjected to Lateral Impact. Maritime Engineering and Technology, Taylor \& Francis Group, London.

[6] Ma, N., Takada, K. and Satoh, K. (2014) Measurement of Local Strain Path and Identification of Ductile Damage Limit by Simple Tensile Test. Engineering Procedia, 81, 1402-1407. http://dx.doi.org/10.1016/j.proeng.2014.10.164

[7] Takada, K., Sato, K. and Ma, N. (2015) Fracture Prediction for Automotive Bodies Using a Ductile Fracture Criterion and a Strain-Dependent Anisotropy Model, Fracture Prediction for Automotive Bodies Using a Ductile Fracture Criterion and a Strain-Dependent Anisotropy Model. SAE International, 8, 803-813. http://dx.doi.org/10.4271/2015-01-0567

[8] Abdel-Nasser, Y., Ma, N., Murakawa, H. and El-Malah, I. (2015) Impact Analysis of Aluminum-Fiber Composite Lamina, Quarterly Journal of Japan Welding Society, 33, 166s-170s. http://dx.doi.org/10.2207/qjjws.33.166s

[9] Ueda, Y., Murakawa, H. and Ma, N. (2012) Welding Deformation and Residual Stress Prevention. 1st Edition, Elsevier, Butterworth-Heinemann.

[10] ABAQUS/Imlicit Software, Version 6.13, Osaka, Japan.

[11] Ninshu, M.A., Chiyonobu, M. and Hisamori, T. (2008) Analysis of Welded and Stamped Members under Impact Loading. Proceedings of International Symposium on Structure under Earthquake, Impact and Blast Loading, 2008, 62-65.

[12] Murakawa, H., Ma, N. and Huang, H. (2015) Iterative Substructure Method Employing Concept of Inherent Strain for Large-Scale Welding Problems. Welding in the World, 59, 53-63. 